\title{
General Split Feasibility Problems in Hilbert Spaces
}

\author{
Mohammad Eslamian ${ }^{1}$ and Abdul Latif ${ }^{2}$ \\ ${ }^{1}$ Young Researchers Club, Babol Branch, Islamic Azad University, Babol, Iran \\ ${ }^{2}$ Department of Mathematics, King Abdulaziz University, P.O. Box 80203, Jeddah 21589, Saudi Arabia
}

Correspondence should be addressed to Abdul Latif; latifmath@yahoo.com

Received 25 October 2012; Accepted 23 December 2012

Academic Editor: Qamrul Hasan Ansari

Copyright (c) 2013 M. Eslamian and A. Latif. This is an open access article distributed under the Creative Commons Attribution License, which permits unrestricted use, distribution, and reproduction in any medium, provided the original work is properly cited.

Introducing a general split feasibility problem in the setting of infinite-dimensional Hilbert spaces, we prove that the sequence generated by the purposed new algorithm converges strongly to a solution of the general split feasibility problem. Our results extend and improve some recent known results.

\section{Introduction}

Let $H$ and $K$ be infinite-dimensional real Hilbert spaces, and let $A: H \rightarrow K$ be a bounded linear operator. Let $\left\{C_{i}\right\}_{i=1}^{p}$ and $\left\{Q_{i}\right\}_{i=1}^{r}$ be the families of nonempty closed convex subsets of $H$ and $K$, respectively.

(a) The convex feasibility problem (CFP) is formulated as the problem of finding a point $x^{\star}$ with the property:

$$
x^{\star} \in \bigcap_{i=1}^{p} C_{i} \text {. }
$$

(b) The split feasibility problem (SEP) is formulated as the problem of finding a point $x^{\star}$ with the property:

$$
x^{\star} \in C, \quad A x^{\star} \in Q,
$$

where $C$ and $Q$ are nonempty closed convex subsets of $H$ and $K$, respectively.

(c) The multiple-set split feasibility problem (MSSFP) is formulated as the problem of finding a point $x^{\star}$ with the property:

$$
x^{\star} \in \bigcap_{i=1}^{p} C_{i}, \quad A x^{\star} \in \bigcap_{i=1}^{r} Q_{i} .
$$

Note that (MSSFP) reduces to (SEP) if we take $p=r=1$.

There is a considerable investigation on CFP in view of its applications in various disciplines such as image restoration, computer tomograph, and radiation therapy treatment planning [1]. The split feasibility problem SFP in the setting of finite-dimensional Hilbert spaces was first introduced by Censor and Elfving [2] for modelling inverse problems which arise from phase retrievals and in medical image reconstruction [3]. Since then, a lot of work has been done on finding a solution of SFP and MSSFP; see, for example, [2-25]. Recently, it is found that the SFP can also be applied to study the intensity-modulated radiation therapy; see, for example, $[6,16]$ and the references therein. Very recently, Xu [8] considered the SFP in the setting of infinite-dimensional Hilbert spaces.

The original algorithm given in [2] involves the computation of the inverse $A^{-1}$ provided it exists. In [8], Xu studied some algorithm and its convergence. In particular, he applied Mann's algorithm to the SFP and purposed an algorithm which is proved to be weakly convergent to a solution of the SFP. He also established the strong convergence result, which shows that the minimum-norm solution can be obtained. In [7], Wang and Xu purposed the following cyclic algorithm to solve MSSFP:

$$
x_{n+1}=P_{C[n]}\left(x_{n}+\gamma A^{*}\left(P_{\mathrm{Q}[n]}-I\right) A x_{n}\right) \text {, }
$$

where $[n]:=n(\bmod p),(\bmod$ function take values in $\{1,2, \ldots, p\})$, and $\gamma \in\left(0,2 /\|A\|^{2}\right)$. They show that the sequence $\left\{x_{n}\right\}$ convergence weakly to a solution of MSSFP provided the solution exists. To study strong convergence to 
a solution of MSSFP, first we introduce a general form of the split feasibility problem for infinite families as follows.

(d) General split feasibility problem (GSFP) is to find a point $x^{*}$ such that

$$
x^{\star} \in \bigcap_{i=1}^{\infty} C_{i}, \quad A x^{\star} \in \bigcap_{i=1}^{\infty} Q_{i} .
$$

We denote by $\Omega$ the solution set of GSFP.

In this paper, using viscosity iterative method defined by Moudafi [21], we propose an algorithm for finding the solutions of the general split feasibility problem in a Hilbert space. We establish the strong convergence of the proposed algorithm to a solution of GSFP.

\section{Preliminaries}

Throughout the paper, we denote by $H$ a real Hilbert space with inner product $\langle\cdot, \cdot\rangle$ and norm $\|\cdot\|$. Let $\left\{x_{n}\right\}$ be a sequence in $H$ and $x \in H$. Weak convergence of $\left\{x_{n}\right\}$ to $x$ is denoted by $x_{n} \rightarrow x$, and strong convergence by $x_{n} \rightarrow x$. Let $C$ be a closed and a convex subset of $H$. For every point $x \in H$, there exists a unique nearest point in $C$, denoted by $P_{C} x$. This point satisfies

$$
\left\|x-P_{C} x\right\| \leq\|x-y\|, \quad \forall y \in C .
$$

The operator $P_{C}$ is called the metric projection or the nearest point mapping of $H$ onto $C$. The metric projection $P_{C}$ is characterized by the fact that $P_{C}(x) \in C$ and

$$
\left\langle y-P_{C}(x), x-P_{C}(x)\right\rangle \leq 0, \quad \forall x \in H, y \in C .
$$

Recall that a mapping $T: C \rightarrow C$ is called nonexpansive if

$$
\|T x-T y\| \leq\|x-y\|, \quad \forall x, y \in C .
$$

It is well known that $P_{C}$ is a nonexpansive mapping. It is also known that $H$ satisfies Opial's condition, that is, for any sequence $\left\{x_{n}\right\}$ with $x_{n} \rightarrow x$, the inequality

$$
\liminf _{n \rightarrow \infty}\left\|x_{n}-x\right\|<\liminf _{n \rightarrow \infty}\left\|x_{n}-y\right\|
$$

holds for every $y \in H$ with $y \neq x$.

Lemma 1. Let $H$ be a Hilbert space. Then, for all $x, y \in H$

$$
\|x+y\|^{2} \leq\|x\|^{2}+2\langle y, x+y\rangle .
$$

Lemma 2 (see [22]). Let $H$ be a Hilbert space, and let $\left\{x_{n}\right\}$ be a sequence in $H$. Then, for any given sequence $\left\{\lambda_{n}\right\}_{n=1}^{\infty} \subset(0,1)$ with $\sum_{n=1}^{\infty} \lambda_{n}=1$ and for any positive integer $i, j$ with $i<j$,

$$
\left\|\sum_{n=1}^{\infty} \lambda_{n} x_{n}\right\|^{2} \leq \sum_{n=1}^{\infty} \lambda_{n}\left\|x_{n}\right\|^{2}-\lambda_{i} \lambda_{j}\left\|x_{i}-x_{j}\right\|^{2} .
$$

Lemma 3 (see [23]). Assume that $\left\{a_{n}\right\}$ is a sequence of nonnegative real numbers such that

$$
a_{n+1} \leq\left(1-\gamma_{n}\right) a_{n}+\gamma_{n} \delta_{n}+\beta_{n}, \quad n \geq 0,
$$

where $\left\{\gamma_{n}\right\},\left\{\beta_{n}\right\}$, and $\left\{\delta_{n}\right\}$ satisfy the following conditions:

(i) $\gamma_{n} \subset[0,1], \sum_{n=1}^{\infty} \gamma_{n}=\infty$,

(ii) $\lim \sup _{n \rightarrow \infty} \delta_{n} \leq 0$ or $\sum_{n=1}^{\infty}\left|\gamma_{n} \delta_{n}\right|<\infty$,

(iii) $\beta_{n} \geq 0$ for all $n \geq 0$ with $\sum_{n=0}^{\infty} \beta_{n}<\infty$.

Then, $\lim _{n \rightarrow \infty} a_{n}=0$.

Lemma 4 (see [24]). Let $\left\{t_{n}\right\}$ be a sequence of real numbers such that there exists a subsequence $\left\{n_{i}\right\}$ of $\{n\}$ such that $t_{n_{i}}<$ $t_{n_{i}+1}$ for all $i \in \mathbb{N}$. Then, there exists a nondecreasing sequence $\{\tau(n)\} \subset \mathbb{N}$ such that $\tau(n) \rightarrow \infty$, and the following properties are satisfied by all (sufficiently large) numbers $n \in \mathbb{N}$ :

$$
t_{\tau(n)} \leq t_{\tau(n)+1}, \quad t_{n} \leq t_{\tau(n)+1} .
$$

In fact

$$
\tau(n)=\max \left\{k \leq n: t_{k}<t_{k+1}\right\} .
$$

Lemma 5 (demiclosedness principle [25]). Let $C$ be a nonempty closed and convex subset of a real Hilbert space $H$. Let $T: C \rightarrow C$ be a nonexpansive mapping such that $\operatorname{Fix}(T) \neq \emptyset$. Then, $T$ is demiclosed on $C$, that is, if $y_{n} \rightarrow z \in C$, and $\left(y_{n}-\right.$ $\left.T y_{n}\right) \rightarrow y$, then $(I-T) z=y$.

\section{Main Result}

In the following result, we propose an algorithm and prove that the sequence generated by the proposed method converges strongly to a solution of the GSFP.

Theorem 6. Let $H$ and $K$ be real Hilbert spaces, and let $A$ : $H \rightarrow K$ be a bounded linear operator. Let $\left\{C_{i}\right\}_{i=1}^{\infty}$ and $\left\{Q_{i}\right\}_{i=1}^{\infty}$ be the families of nonempty closed convex subsets of $H$ and $K$, respectively. Assume that GSFP (5) has a nonempty solution set $\Omega$. Suppose that $f$ is a selfk-contraction mapping of $H$, and let $\left\{x_{n}\right\}$ be a sequence generated by $x_{0} \in H$ as

$$
\begin{aligned}
x_{n+1}= & \alpha_{n} x_{n}+\beta_{n} f\left(x_{n}\right) \\
& +\sum_{i=1}^{\infty} \gamma_{n, i} P_{C_{i}}\left(I-\lambda_{n, i} A^{*}\left(I-P_{\mathrm{Q}_{i}}\right) A\right) x_{n}, \quad n \geq 0,
\end{aligned}
$$

where $\alpha_{n}+\beta_{n}+\sum_{i=1}^{\infty} \gamma_{n, i}=1$. If the sequences $\left\{\alpha_{n}\right\},\left\{\beta_{n}\right\},\left\{\gamma_{n, i}\right\}$, and $\left\{\lambda_{n, i}\right\}$ satisfy the following conditions:

(i) $\lim _{n \rightarrow \infty} \beta_{n}=0$ and $\sum_{n=0}^{\infty} \beta_{n}=\infty$,

(ii) for each $i \in \mathbb{N}, \liminf _{n} \alpha_{n} \gamma_{n, i}>0$,

(iii) for each $i \in \mathbb{N},\left\{\lambda_{n, i}\right\} \subset\left(0,2 /\|A\|^{2}\right)$ and $0<$ $\liminf _{n \rightarrow \infty} \lambda_{n, i} \leq \limsup _{n \rightarrow \infty} \lambda_{n, i}<2 /\|A\|^{2}$,

then, the sequence $\left\{x_{n}\right\}$ converges strongly to $x^{\star} \in \Omega$, where $x^{\star}=P_{\Omega} f\left(x^{\star}\right)$. 
Proof. First, we show that $\left\{x_{n}\right\}$ is bounded. In fact, let $z \in \Omega$. Since $\left\{\lambda_{n, i}\right\} \subset\left(0,2 /\|A\|^{2}\right)$, the operators $P_{C_{i}}\left(I-\lambda_{n, i} A^{*}(I-\right.$ $\left.P_{Q_{i}}\right) A$ ) are nonexpansive, and hence we have

$$
\begin{aligned}
& \left\|x_{n+1}-z\right\| \\
& =\alpha_{n} x_{n}+\beta_{n} f\left(x_{n}\right) \\
& +\sum_{i=1}^{\infty} \gamma_{n, i} P_{C_{i}}\left(I-\lambda_{n, i} A^{*}\left(I-P_{\mathrm{Q}_{i}}\right) A\right) x_{n}-z \| \\
& \leq \alpha_{n}\left\|x_{n}-z\right\|+\beta_{n}\left\|f\left(x_{n}\right)-z\right\| \\
& +\sum_{i=1}^{\infty} \gamma_{n, i}\left\|P_{C_{i}}\left(I-\lambda_{n, i} A^{*}\left(I-P_{Q_{i}}\right) A\right) x_{n}-z\right\| \\
& \leq \alpha_{n}\left\|x_{n}-z\right\|+\beta_{n}\left\|f\left(x_{n}\right)-z\right\| \\
& +\sum_{i=1}^{\infty} \gamma_{n, i}\left\|x_{n}-z\right\| \\
& \leq\left(1-\beta_{n}\right)\left\|x_{n}-z\right\|+\beta_{n}\left\|f\left(x_{n}\right)-z\right\| \\
& \leq\left(1-\beta_{n}\right)\left\|x_{n}-z\right\|+\beta_{n}\left\|f\left(x_{n}\right)-f(z)\right\| \\
& +\beta_{n}\|f(z)-z\| \\
& \leq\left(1-\beta_{n}\right)\left\|x_{n}-z\right\|+\beta_{n} k\left\|x_{n}-z\right\| \\
& +\beta_{n}\|f(z)-z\| \\
& \leq(1-(1-k)) \beta_{n}\left\|x_{n}-z\right\| \\
& +(1-k) \frac{\beta_{n}}{1-k}\|f(z)-z\| \\
& \leq \max \left\{\left\|x_{n}-z\right\|, \frac{1}{1-k}\|f(z)-z\|\right\} \\
& \vdots \\
& \leq \max \left\{\left\|x_{0}-z\right\|, \frac{1}{1-k}\|f(z)-z\|\right\},
\end{aligned}
$$

which implies that $\left\{x_{n}\right\}$ is bounded, and we also obtain that $\left\{f\left(x_{n}\right)\right\}$ is bounded. Next, we show that for each $i \in \mathbb{N}$,

$$
\lim _{n \rightarrow \infty}\left\|x_{n}-P_{C_{i}}\left(I-\lambda_{n, i} A^{*}\left(I-P_{Q_{i}}\right) A\right) x_{n}\right\|=0 .
$$

By using Lemma 2, for every $z \in \Omega$ and $i \in \mathbb{N}$, we have that

$$
\begin{aligned}
& \left\|x_{n+1}-z\right\|^{2} \\
& =\| \alpha_{n} x_{n}+\beta_{n} f\left(x_{n}\right) \\
& \quad+\sum_{j=1}^{\infty} \gamma_{n, j} P_{C_{j}}\left(I-\lambda_{n, j} A^{*}\left(I-P_{Q_{j}}\right) A\right) x_{n}-z \|^{2}
\end{aligned}
$$

$$
\begin{aligned}
\leq & \alpha_{n}\left\|x_{n}-z\right\|^{2}+\beta_{n}\left\|f\left(x_{n}\right)-z\right\|^{2} \\
& +\sum_{j=1}^{\infty} \gamma_{n, j}\left\|P_{C_{j}}\left(I-\lambda_{n, j} A^{*}\left(I-P_{Q_{j}}\right) A\right) x_{n}-z\right\|^{2} \\
& -\alpha_{n} \gamma_{n, i}\left\|P_{C_{i}}\left(I-\lambda_{n, i} A^{*}\left(I-P_{Q_{i}}\right) A\right) x_{n}-x_{n}\right\|^{2} \\
\leq & \alpha_{n}\left\|x_{n}-z\right\|^{2}+\beta_{n}\left\|f\left(x_{n}\right)-z\right\|^{2} \\
& +\sum_{j=1}^{\infty} \gamma_{n, j}\left\|x_{n}-z\right\|^{2} \\
& -\alpha_{n} \gamma_{n, i}\left\|P_{C_{i}}\left(I-\lambda_{n, i} A^{*}\left(I-P_{Q_{i}}\right) A\right) x_{n}-x_{n}\right\|^{2} \\
\leq & \left(1-\beta_{n}\right)\left\|x_{n}-z\right\|^{2}+\beta_{n}\left\|f\left(x_{n}\right)-z\right\|^{2} \\
& -\alpha_{n} \gamma_{n, i}\left\|P_{C_{i}}\left(I-\lambda_{n, i} A^{*}\left(I-P_{Q_{i}}\right) A\right) x_{n}-x_{n}\right\|^{2} .
\end{aligned}
$$

Hence, for each $i \in \mathbb{N}$, we have

$$
\begin{aligned}
& \alpha_{n} \gamma_{n, i}\left\|P_{C_{i}}\left(I-\lambda_{n, i} A^{*}\left(I-P_{Q_{i}}\right) A\right) x_{n}-x_{n}\right\|^{2} \\
& \quad \leq\left\|x_{n}-z\right\|^{2}-\left\|x_{n+1}-z\right\|^{2}+\beta_{n}\left\|f\left(x_{n}\right)-z\right\|^{2} .
\end{aligned}
$$

Next, we show that there exists a unique $x^{\star} \in \Omega$ such that $x^{\star}=P_{\Omega} f\left(x^{\star}\right)$. We observe that for each $n \geq 0, x^{\star} \in \Omega$ solves the GSFP (5) if and only if $x^{\star}$ solves the fixed point equation

$$
x^{\star}=P_{C_{i}}\left(I-\lambda_{n, i} A^{*}\left(I-P_{\mathrm{Q}_{i}}\right) A\right) x^{\star}, \quad i \in \mathbb{N},
$$

that is, the solution sets of fixed point equation (20) and GSFP (5) are the same (see for details [8]). Note that if $\left\{\lambda_{n, i}\right\} \subset$ $\left(0,2 /\|A\|^{2}\right)$, then the operators $P_{C_{i}}\left(I-\lambda_{n, i} A^{*}\left(I-P_{\mathrm{Q}_{i}}\right) A\right)$ are nonexpansive. Since the fixed point set of nonexpansive operators is closed and convex, the projection onto the solution set $\Omega$ is well defined whenever $\Omega \neq \emptyset$. We observe that $P_{\Omega}(f)$ is a contraction of $H$ into itself. Indeed, since $P_{\Omega}$ is nonexpansive,

$$
\left\|P_{\Omega}(f)(x)-P_{\Omega}(f)(y)\right\| \leq\|f(x)-f(y)\| \leq k\|x-y\| .
$$

Hence, there exists a unique element $x^{\star} \in \Omega$ such that $x^{\star}=$ $P_{\Omega} f\left(x^{\star}\right)$.

In order to prove that $x_{n} \rightarrow x^{\star}$ as $n \rightarrow \infty$, we consider two possible cases.

Case 1. Assume that $\left\{\left\|x_{n}-x^{\star}\right\|\right\}$ is a monotone sequence. In other words, for $n_{0}$ large enough, $\left\{\left\|x_{n}-x^{\star}\right\|\right\}_{n \geq n_{0}}$ is either nondecreasing or nonincreasing. Since $\left\|x_{n}-x^{\star}\right\|$ is bounded we have $\left\|x_{n}-x^{\star}\right\|$ is convergent. Since $\lim _{n \rightarrow \infty} \beta_{n}=0$ and $\left\{f\left(x_{n}\right)\right\}$ is bounded, from (19) we get that

$$
\lim _{n \rightarrow \infty} \alpha_{n} \gamma_{n, i}\left\|P_{C_{i}}\left(I-\lambda_{n, i} A^{*}\left(I-P_{Q_{i}}\right) A\right) x_{n}-x_{n}\right\|^{2}=0 .
$$


By assuming that $\lim \inf _{n} \alpha_{n} \gamma_{n, i}>0$, we obtain

$\lim _{n \rightarrow \infty}\left\|P_{C_{i}}\left(I-\lambda_{n, i} A^{*}\left(I-P_{Q_{i}}\right) A\right) x_{n}-x_{n}\right\|=0, \quad \forall i \in \mathbb{N}$.

Now, we show that

$$
\limsup _{n \rightarrow \infty}\left\langle f\left(x^{\star}\right)-x^{\star}, x_{n}-x^{\star}\right\rangle \leq 0 .
$$

To show this inequality, we choose a subsequence $\left\{x_{n_{k}}\right\}$ of $\left\{x_{n}\right\}$ such that

$$
\begin{aligned}
& \lim _{k \rightarrow \infty}\left\langle f\left(x^{\star}\right)-x^{\star}, x_{n_{k}}-x^{\star}\right\rangle \\
& \quad=\limsup _{n \rightarrow \infty}\left\langle f\left(x^{\star}\right)-x^{\star}, x_{n}-x^{\star}\right\rangle .
\end{aligned}
$$

Since $\left\{x_{n_{k}}\right\}$ is bounded, there exists a subsequence $\left\{x_{n_{k_{j}}}\right\}$ of $\left\{x_{n_{k}}\right\}$ which converges weakly to $w$. Without loss of generality, we can assume that $x_{n_{k}} \rightarrow w$ and $\lambda_{n, i} \rightarrow \lambda_{i} \in\left(0,2 /\|A\|^{2}\right)$ for each $i \in \mathbb{N}$. From (23), we have

$$
\begin{aligned}
\left\|P_{C_{i}}\left(I-\lambda_{i} A^{*}\left(I-P_{\mathrm{Q}_{i}}\right) A\right) x_{n}-x_{n}\right\| \\
\leq \| P_{C_{i}}\left(I-\lambda_{i} A^{*}\left(I-P_{\mathrm{Q}_{i}}\right) A\right) x_{n} \\
\quad-P_{C_{i}}\left(I-\lambda_{n, i} A^{*}\left(I-P_{\mathrm{Q}_{i}}\right) A\right) x_{n} \| \\
+\left\|P_{C_{i}}\left(I-\lambda_{n, i} A^{*}\left(I-P_{\mathrm{Q}_{i}}\right) A\right) x_{n}-x_{n}\right\| \\
\leq \|\left(I-\lambda_{i} A^{*}\left(I-P_{\mathrm{Q}_{i}}\right) A\right) x_{n} \\
\quad-\left(I-\lambda_{n, i} A^{*}\left(I-P_{\mathrm{Q}_{i}}\right) A\right) x_{n} \| \\
\quad+\left\|P_{C_{i}}\left(I-\lambda_{n, i} A^{*}\left(I-P_{\mathrm{Q}_{i}}\right) A\right) x_{n}-x_{n}\right\| \\
\leq \quad\left|\lambda_{i}-\lambda_{n, i}\right|\left\|A^{*}\left(I-P_{\mathrm{Q}_{i}}\right) A x_{n}\right\| \\
\quad+\left\|P_{C_{i}}\left(I-\lambda_{n, i} A^{*}\left(I-P_{\mathrm{Q}_{i}}\right) A\right) x_{n}-x_{n}\right\| \\
\longrightarrow
\end{aligned}
$$

Notice that for each $i \in \mathbb{N}, P_{C_{i}}\left(I-\lambda_{i} A^{*}\left(I-P_{\mathrm{Q}_{i}}\right) A\right)$ is nonexpansive. Thus, from Lemma 5, we have $w \in \Omega$. Therefore, it follows that

$$
\begin{aligned}
& \limsup _{n \rightarrow \infty}\left\langle f\left(x^{\star}\right)-x^{\star}, x_{n}-x^{\star}\right\rangle \\
& =\lim _{k \rightarrow \infty}\left\langle f\left(x^{\star}\right)-x^{\star}, x_{n_{k}}-x^{\star}\right\rangle \\
& =\left\langle f\left(x^{\star}\right)-x^{\star}, w-x^{\star}\right\rangle \leq 0 .
\end{aligned}
$$

Finally, we show that $x_{n} \rightarrow P_{\Omega} f\left(x^{\star}\right)$. Applying Lemma 1, we have that

$$
\begin{aligned}
\| x_{n+1} & -x^{\star} \|^{2} \\
= & \| \alpha_{n}\left(x_{n}-x^{\star}\right) \\
& +\sum_{i=1}^{\infty} \gamma_{n, i}\left(P_{C_{i}}\left(I-\lambda_{n, i} A^{*}\left(I-P_{Q_{i}}\right) A\right) x_{n}-x^{\star}\right) \|^{2} \\
& +2 \beta_{n}\left\langle f\left(x_{n}\right)-x^{\star}, x_{n+1}-x^{\star}\right\rangle \\
\leq & \left(1-\beta_{n}\right)^{2}\left\|x_{n}-x^{\star}\right\|^{2} \\
& +2 \beta_{n}\left\langle f\left(x_{n}\right)-f\left(x^{\star}\right), x_{n+1}-x^{\star}\right\rangle \\
& +2 \beta_{n}\left\langle f\left(x^{\star}\right)-x^{\star}, x_{n+1}-x^{\star}\right\rangle \\
\leq & \left(1-\beta_{n}\right)^{2}\left\|x_{n}-x^{\star}\right\|^{2} \\
& +2 \beta_{n} k\left\|x_{n}-x^{\star}\right\|\left\|x_{n+1}-x^{\star}\right\| \\
& +2 \beta_{n}\left\langle f\left(x^{\star}\right)-x^{\star}, x_{n+1}-x^{\star}\right\rangle \\
\leq & \left(1-\beta_{n}\right)^{2}\left\|x_{n}-x^{\star}\right\|^{2} \\
& +\beta_{n} k\left\{\left\|x_{n}-x^{\star}\right\|^{2}+\left\|x_{n+1}-x^{\star}\right\|^{2}\right\} \\
& +2 \beta_{n}\left\langle f\left(x^{\star}\right)-x^{\star}, x_{n+1}-x^{\star}\right\rangle .
\end{aligned}
$$

This implies that

$$
\begin{aligned}
& \| x_{n+1}-x^{\star} \|^{2} \\
& \leq \frac{\left(1-\beta_{n}\right)^{2}+\beta_{n} k}{1-\beta_{n} k}\left\|x_{n}-x^{\star}\right\|^{2} \\
&+\frac{2 \beta_{n}}{1-\beta_{n} k}\left\langle f\left(x^{\star}\right)-x^{\star}, x_{n+1}-x^{\star}\right\rangle \\
&= \frac{1-2 \beta_{n}+\beta_{n} k}{1-\beta_{n} k}\left\|x_{n}-x^{\star}\right\|^{2} \\
&+\frac{\beta_{n}^{2}}{1-\beta_{n} k}\left\|x_{n}-x^{\star}\right\|^{2} \\
&+\frac{2 \beta_{n}}{1-\beta_{n} k}\left\langle f(z)-x^{\star}, x_{n+1}-x^{\star}\right\rangle \\
& \leq\left(1-\frac{2(1-k) \beta_{n}}{1-\beta_{n} k}\right)\left\|x_{n}-x^{\star}\right\|^{2} \\
& \leq\left(1-\eta_{n}\right)\left\|x_{n}-x^{\star}\right\|^{2}+\eta_{n} \delta_{n}, \\
&+\frac{2(1-k) \beta_{n}}{1-\beta_{n} k}\left\{\frac{\beta_{n} M}{2(1-k)}\right. \\
&\left.+\frac{1}{1-k}\left\langle f\left(x^{\star}\right)-x^{\star}, x_{n+1}-x^{\star}\right\rangle\right\}
\end{aligned}
$$


where

$$
\delta_{n}=\frac{\beta_{n} M}{2(1-k)}+\frac{1}{1-k}\left\langle f\left(x^{\star}\right)-x^{\star}, x_{n+1}-x^{\star}\right\rangle,
$$

$M=\sup \left\{\left\|x_{n}-x^{\star}\right\|^{2}: n \geq 0\right\}$ and $\eta_{n}=2(1-k) \beta_{n} /\left(1-\beta_{n} k\right)$. It is easy to see that $\eta_{n} \rightarrow 0, \sum_{n=1}^{\infty} \eta_{n}=\infty$ and $\lim \sup _{n \rightarrow \infty} \delta_{n} \leq$ 0 . Hence, by Lemma 3 , the sequence $\left\{x_{n}\right\}$ converges strongly to $x^{\star}=P_{\Omega} f\left(x^{\star}\right)$.

Case 2. Assume that $\left\{\left\|x_{n}-x^{\star}\right\|\right\}$ is not a monotone sequence. Then, we can define an integer sequence $\{\tau(n)\}$ for all $n \geq n_{0}$ (for some $n_{0}$ large enough) by

$$
\tau(n)=\max \left\{k \in \mathbb{N} ; k \leq n:\left\|x_{k}-x^{\star}\right\|<\left\|x_{k+1}-x^{\star}\right\|\right\} .
$$

Clearly, $\tau(n)$ is a nondecreasing sequence such that $\tau(n) \rightarrow$ $\infty$ as $n \rightarrow \infty$ and for all $n \geq n_{0}$,

$$
\left\|x_{\tau(n)}-x^{\star}\right\|<\left\|x_{\tau(n)+1}-x^{\star}\right\| .
$$

From (19), we obtain that

$$
\lim _{n \rightarrow \infty}\left\|P_{C_{i}}\left(I-\lambda_{\tau(n), i} A^{*}\left(I-P_{Q_{i}}\right) A\right) x_{\tau(n)}-x_{\tau(n)}\right\|=0 .
$$

Following an argument similar to that in Case 1, we have

$$
\limsup _{n \rightarrow \infty}\left\langle f\left(x^{\star}\right)-x^{\star}, x_{\tau(n)+1}-x^{\star}\right\rangle \leq 0 .
$$

And by similar argument, we have

$$
\begin{aligned}
& \left\|x_{\tau(n)+1}-x^{\star}\right\|^{2} \\
& \quad \leq\left(1-\eta_{\tau(n)}\right)\left\|x_{\tau(n)}-x^{\star}\right\|^{2}+\eta_{\tau(n)} \delta_{\tau(n)},
\end{aligned}
$$

where $\eta_{\tau(n)} \rightarrow 0, \sum_{n=1}^{\infty} \eta_{\tau(n)}=\infty$ and $\lim \sup _{n \rightarrow \infty} \delta_{\tau(n)} \leq 0$. Hence, by Lemma 3, we obtain $\lim _{n \rightarrow \infty}\left\|x_{\tau(n)}-x^{\star}\right\|=0$ and $\lim _{n \rightarrow \infty}\left\|x_{\tau(n)+1}-x^{\star}\right\|=0$. Now, from Lemma 4 , we have

$$
\begin{aligned}
0 & \leq\left\|x_{n}-x^{\star}\right\| \\
& \leq \max \left\{\left\|x_{\tau(n)}-x^{\star}\right\|,\left\|x_{n}-x^{\star}\right\|\right\} \\
& \leq\left\|x_{\tau(n)+1}-x^{\star}\right\| .
\end{aligned}
$$

Therefore, $\left\{x_{n}\right\}$ converges strongly to $x^{\star}=P_{\Omega} f\left(x^{\star}\right)$.

For finite collections we have the following consequence of Theorem 6.

Theorem 7. Let $H$ and $K$ be real Hilbert spaces, and let $A$ : $H \rightarrow K$ be a bounded linear operator. Let $\left\{C_{i}\right\}_{i=1}^{p}$ be a family of nonempty closed convex subsets in $H$, and let $\left\{Q_{i}\right\}_{i=1}^{p}$ be a family of nonempty closed convex subsets in $K$. Assume that MSSFP has a nonempty solution set $\Omega$. Let $u$ be an arbitrary element in $H$, and let $\left\{x_{n}\right\}$ be a sequence generated by $x_{0} \in H$ and

$$
\begin{aligned}
x_{n+1}= & \alpha_{n} x_{n}+\beta_{n} u \\
& +\sum_{i=1}^{p} \gamma_{n, i} P_{C_{i}}\left(I-\lambda_{n, i} A^{*}\left(I-P_{\mathrm{Q}_{i}}\right) A\right) x_{n}, \quad n \geq 0,
\end{aligned}
$$

where $\alpha_{n}+\beta_{n}+\sum_{i=1}^{p} \gamma_{n, i}=1$. If the sequences $\left\{\alpha_{n}\right\},\left\{\beta_{n}\right\},\left\{\gamma_{n, i}\right\}$, and $\left\{\lambda_{n, i}\right\}$ satisfy the following conditions:

(i) $\lim _{n \rightarrow \infty} \beta_{n}=0$ and $\sum_{n=0}^{\infty} \beta_{n}=\infty$,

(ii) for all $i \in\{1,2, \ldots, p\}, \liminf _{n} \alpha_{n} \gamma_{n, i}>0$,

(iii) for all $i \in\{1,2, \ldots, p\},\left\{\lambda_{n, i}\right\} \subset\left(0,2 /\|A\|^{2}\right)$ and

$$
0<\liminf _{n \rightarrow \infty} \lambda_{n, i} \leq \limsup _{n \rightarrow \infty} \lambda_{n, i}<\frac{2}{\|A\|^{2}}
$$

then the sequence $\left\{x_{n}\right\}$ converges strongly to $x^{\star} \in \Omega$, where $x^{\star}=P_{\Omega} u$.

\section{Acknowledgment}

This paper is funded by the Deanship of Scientific Research (DSR), King Abdulaziz University, Jeddah. The authors therefore, acknowledge with thanks the DSR for technical and financial support.

\section{References}

[1] P. L. Combettes, "The convex feasibility problem in image recovery," in Advances in Imaging and Electron Physics, P. Hawkes, Ed., vol. 95, pp. 155-270, Academic Press, New York, NY, USA, 1996.

[2] Y. Censor and T. Elfving, "A multiprojection algorithm using Bregman projections in a product space," Numerical Algorithms, vol. 8, no. 2-4, pp. 221-239, 1994.

[3] C. Byrne, "Iterative oblique projection onto convex sets and the split feasibility problem," Inverse Problems, vol. 18, no. 2, pp. 441453, 2002.

[4] L.-C. Ceng, Q. H. Ansari, and J.-C. Yao, "Relaxed extragradient methods for finding minimum-norm solutions of the split feasibility problem," Nonlinear Analysis: Theory, Methods \& Applications, vol. 75, no. 4, pp. 2116-2125, 2012.

[5] L.-C. Ceng, Q. H. Ansari, and J.-C. Yao, "An extragradient method for solving split feasibility and fixed point problems," Computers \& Mathematics with Applications, vol. 64, no. 4, pp. 633-642, 2012.

[6] Y. Censor, T. Elfving, N. Kopf, and T. Bortfeld, "The multiplesets split feasibility problem and its applications for inverse problems," Inverse Problems, vol. 21, no. 6, pp. 2071-2084, 2005.

[7] F. Wang and H.-K. Xu, "Cyclic algorithms for split feasibility problems in Hilbert spaces," Nonlinear Analysis: Theory, Methods \& Applications, vol. 74, no. 12, pp. 4105-4111, 2011.

[8] H.-K. Xu, "Iterative methods for the split feasibility problem in infinite-dimensional Hilbert spaces," Inverse Problems, vol. 26, no. 10, Article ID 105018, p. 17, 2010.

[9] Y. Censor, A. Motova, and A. Segal, "Perturbed projections and subgradient projections for the multiple-sets split feasibility problem," Journal of Mathematical Analysis and Applications, vol. 327, no. 2, pp. 1244-1256, 2007.

[10] H.-K. Xu, “A variable Krasnosel'skii-Mann algorithm and the multiple-set split feasibility problem," Inverse Problems, vol. 22, no. 6, pp. 2021-2034, 2006.

[11] Q. Yang, "The relaxed CQ algorithm solving the split feasibility problem," Inverse Problems, vol. 20, no. 4, pp. 1261-1266, 2004. 
[12] H. H. Bauschke and J. M. Borwein, "On projection algorithms for solving convex feasibility problems," SIAM Review, vol. 38, no. 3, pp. 367-426, 1996.

[13] Y. Alber and D. Butnariu, "Convergence of Bregman projection methods for solving consistent convex feasibility problems in reflexive Banach spaces," Journal of Optimization Theory and Applications, vol. 92, no. 1, pp. 33-61, 1997.

[14] B. Qu and N. Xiu, "A note on the CQ algorithm for the split feasibility problem," Inverse Problems, vol. 21, no. 5, pp. 1655$1665,2005$.

[15] J. Zhao and Q. Yang, "Several solution methods for the split feasibility problem," Inverse Problems, vol. 21, no. 5, pp. 17911799, 2005.

[16] Y. Censor and A. Segal, "The split common fixed point problem for directed operators," Journal of Convex Analysis, vol. 16, no. 2, pp. 587-600, 2009.

[17] Y. Yao, W. Jigang, and Y.-C. Liou, "Regularized methods for the split feasibility problem," Abstract and Applied Analysis, vol. 2012, Article ID 140679, 13 pages, 2012.

[18] Y. Dang and Y. Gao, “The strong convergence of a KM-CQ-like algorithm for a split feasibility problem," Inverse Problems, vol. 27, article 015007, p. 9, 2011.

[19] F. Wang and H.-K. Xu, "Approximating curve and strong convergence of the CQ algorithm for the split feasibility problem," Journal of Inequalities and Applications, vol. 2010, Article ID 102085, 13 pages, 2010.

[20] L.-C. Ceng, Q. H. Ansari, and J.-C. Yao, "Mann type iterative methods for finding a common solution of split feasibility and fixed point problems," Positivity, vol. 16, no. 3, pp. 471-495, 2012.

[21] A. Moudafi, "Viscosity approximation methods for fixed-points problems," Journal of Mathematical Analysis and Applications, vol. 241, no. 1, pp. 46-55, 2000.

[22] S.-S. Chang, J. K. Kim, and X. R. Wang, "Modified block iterative algorithm for solving convex feasibility problems in Banach spaces," Journal of Inequalities and Applications, vol. 2010, Article ID 869684, 14 pages, 2010.

[23] H.-K. Xu, "Iterative algorithms for nonlinear operators," Journal of the London Mathematical Society, vol. 66, no. 1, pp. 240-256, 2002.

[24] P.-E. Maingé, "Strong convergence of projected subgradient methods for nonsmooth and nonstrictly convex minimization," Set-Valued Analysis, vol. 16, no. 7-8, pp. 899-912, 2008.

[25] K. Goebel and W. A. Kirk, Topics in Metric Fixed Point Theory, vol. 28, Cambridge University Press, Cambridge, UK, 1990. 


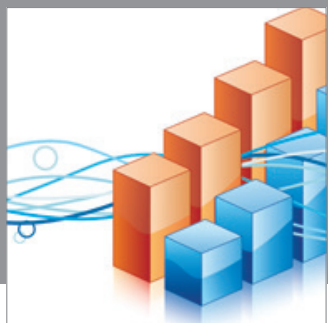

Advances in

Operations Research

mansans

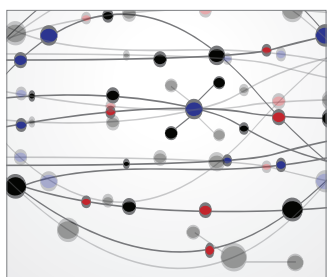

The Scientific World Journal
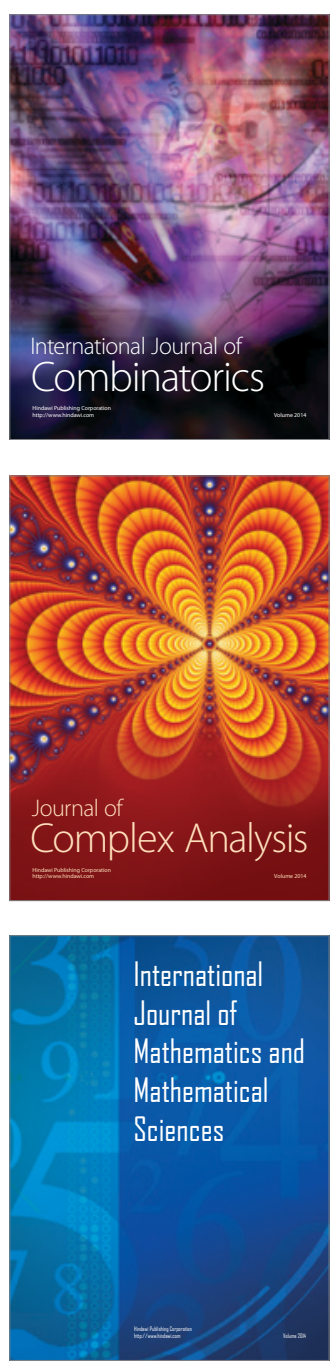
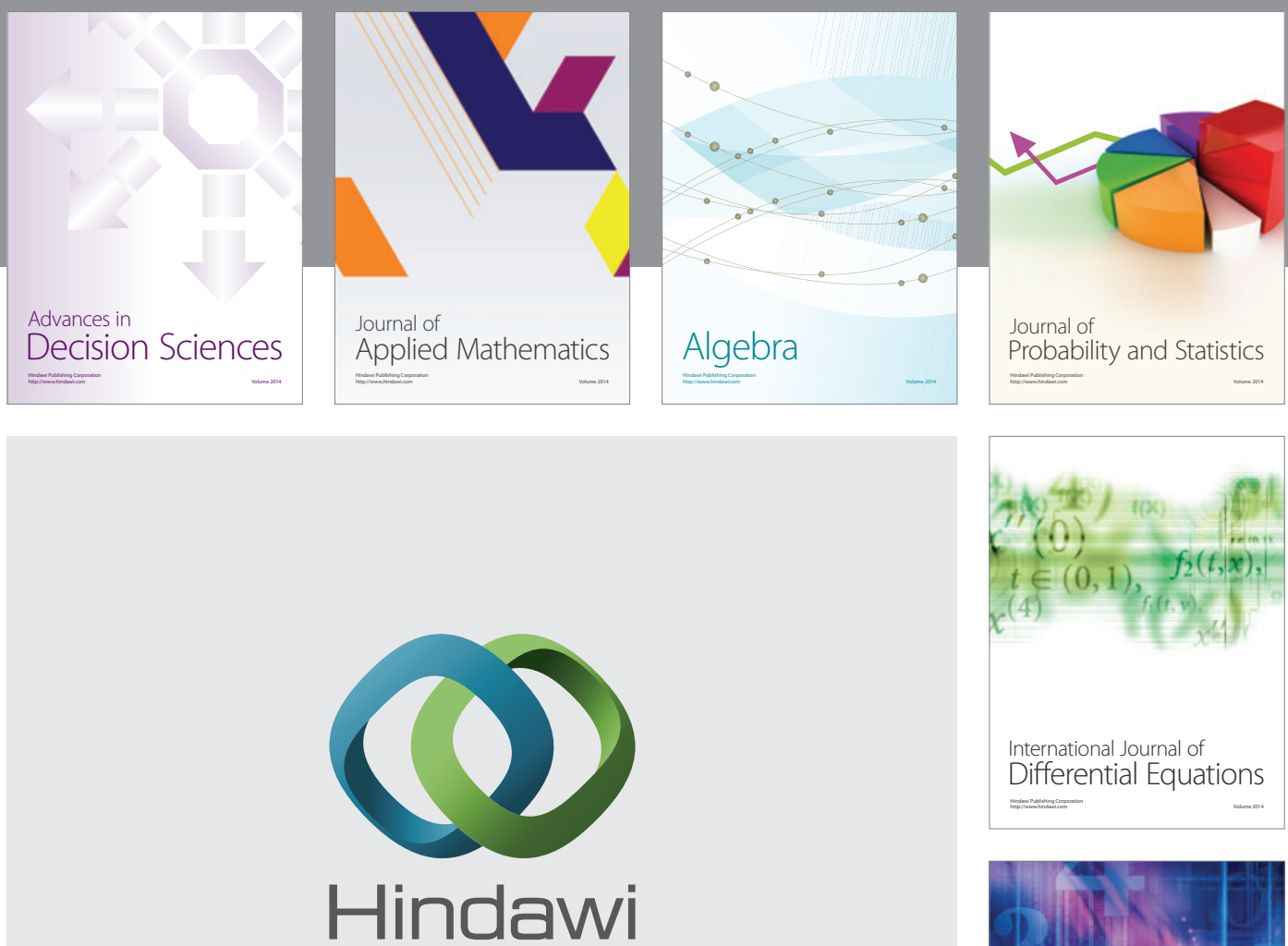

Submit your manuscripts at http://www.hindawi.com
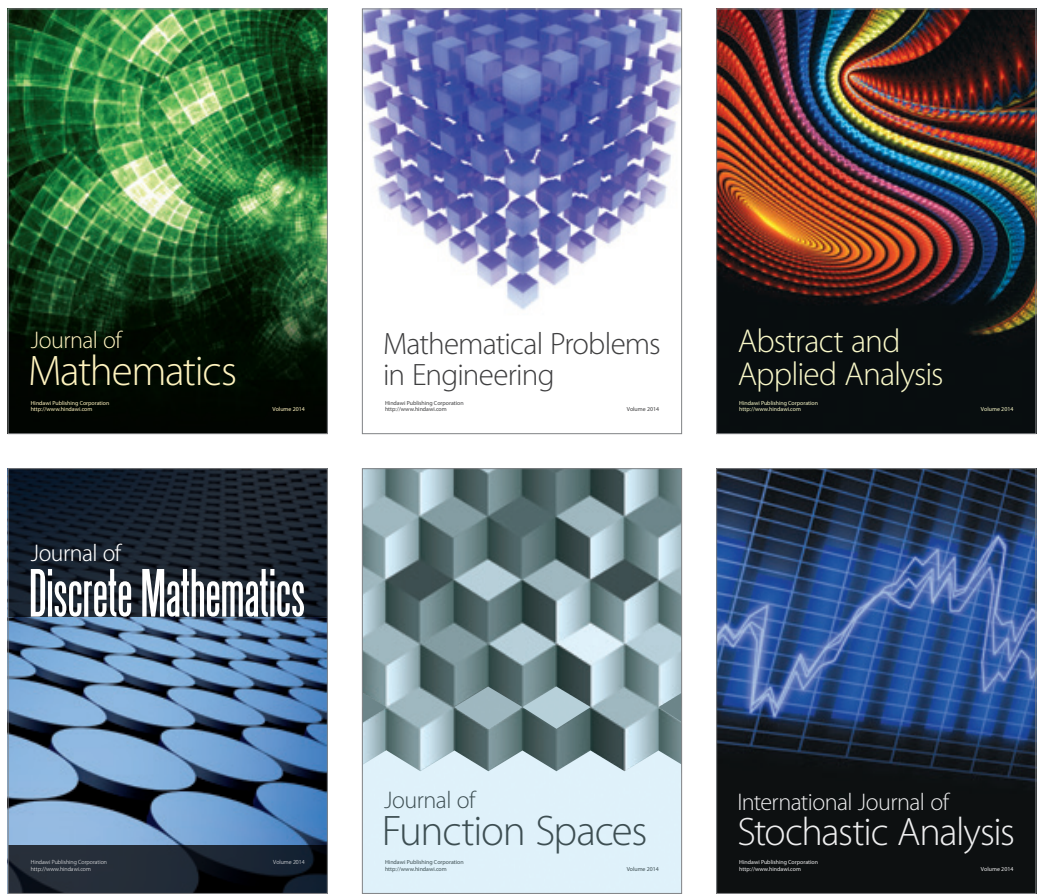

Journal of

Function Spaces

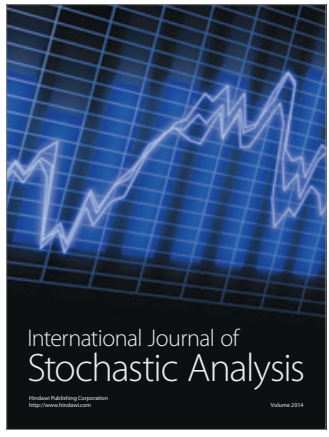

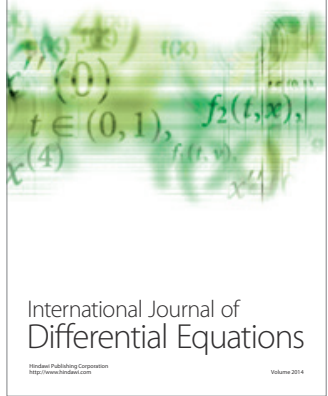
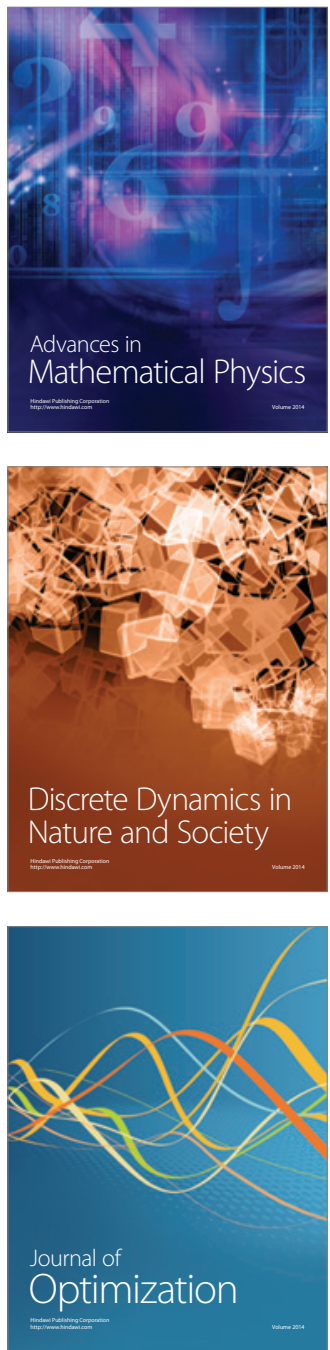